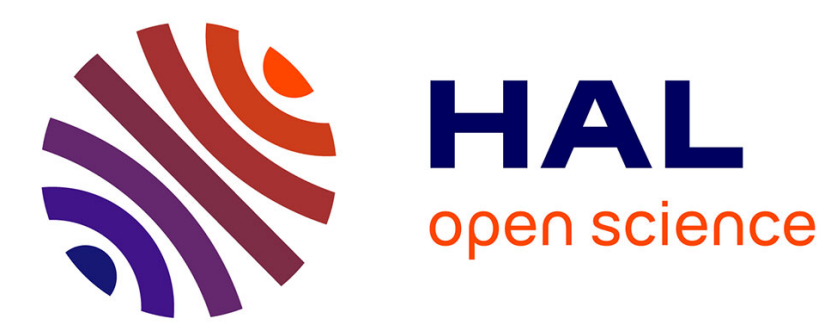

\title{
Influence of surface conductivity on the apparent zeta potential of $\mathrm{TiO} 2$ nanoparticles
}

Philippe Leroy, Christophe Tournassat, Mohamed Bizi

\section{To cite this version:}

Philippe Leroy, Christophe Tournassat, Mohamed Bizi. Influence of surface conductivity on the apparent zeta potential of TiO2 nanoparticles. Journal of Colloid and Interface Science, 2011, 356 (2), pp.442-453. 10.1016/j.jcis.2011.01.016 . hal-00600299

\section{HAL Id: hal-00600299 \\ https: / hal-brgm.archives-ouvertes.fr/hal-00600299}

Submitted on 14 Jun 2011

HAL is a multi-disciplinary open access archive for the deposit and dissemination of scientific research documents, whether they are published or not. The documents may come from teaching and research institutions in France or abroad, or from public or private research centers.
L'archive ouverte pluridisciplinaire $\mathbf{H A L}$, est destinée au dépôt et à la diffusion de documents scientifiques de niveau recherche, publiés ou non, émanant des établissements d'enseignement et de recherche français ou étrangers, des laboratoires publics ou privés. 
The influence of surface conductivity on the apparent zeta potential of $\mathrm{TiO}_{2}$ nanoparticles

Philippe Leroy $^{1 *}$, Christophe Tournassat ${ }^{1}$, Mohamed Bizi ${ }^{1}$

${ }^{1}$ BRGM, French Geological Survey, 3 Avenue C. Guillemin, 45060 Orléans, France

"Corresponding author and mailing address:

Philippe Leroy

BRGM

Water Division (EAU/VAP)

3 Avenue Claude Guillemin

45060 Orléans Cedex 2, France

E-mail: p.leroy@brgm.fr

Tel: +33 (0)2 38643973

Fax: +33(0)2 38643719 


\section{Abstract}

Zeta potential is a physico-chemical parameter of particular importance to describe ion adsorption and electrostatic interactions between charged particles. Nevertheless, this fundamental parameter is ill-constrained, because its experimental interpretation is complex, particularly for very small and charged $\mathrm{TiO}_{2}$ nanoparticles. The excess of electrical charge at the interface is responsible for surface conductance, which can significantly lower the electrophoretic measurements, and hence the apparent zeta potential. Consequently, the intrinsic zeta potential can have a larger amplitude, even in the case of simple 1:1 electrolytes like $\mathrm{NaCl}$ and $\mathrm{KCl}$. Surface conductance of $\mathrm{TiO}_{2}$ nanoparticles immersed in a $\mathrm{NaCl}$ solution is estimated using a surface complexation model, and this parameter and particle size are incorporated into Henry's model in order to determine a constrained value of the zeta potential from electrophoresis. Interior conductivity of the agglomerates is calculated using a differential self-consistent model. The amplitude of estimated zeta potential is greater than that derived from the von Smoluchowski equation and corresponds to the electric potential at the Outer Helmholtz Plane calculated by our surface complexation model. Consequently, the shear plane may be located close to the OHP, contradicting the assumption of the presence of a stagnant diffuse layer at the $\mathrm{TiO}_{2} /$ water interface.

Keywords: zeta potential, electrophoretic mobility, $\mathrm{TiO}_{2}$, nanoparticle, surface conductivity, extended Stern model. 


\section{Introduction}

Titanium dioxide is widely used as $\mathrm{TiO}_{2}$ nanoparticles and has a large variety of potential applications in, for example, the biomedical, optical, and electronic fields [1, 2]. Due to their small size, nanoparticles have a very high surface area to volume ratio and are thus of great scientific interest as they are a bridge between bulk materials and atomic or molecular structures. The properties of materials change as their size decreases to nanoscale and the proportion of surface atoms becomes significant. One of these properties, the surface ionization of titanium dioxide nanoparticles in contact with an electrolytic solution, has been studied extensively [1, 3-10]. It is well known that the complexation reactions at the surface of an oxide mineral are strongly influenced by the development of the surface charge. The primary surface charge is determined by the reactions of protons with the surface. Surface complexation reactions between the surface sites and the ions from the bulk electrolyte at the Stern and in the diffuse layer neutralize the surface charge [11]. Surface charge properties are primarily determined using proton titration data. These data can be modeled using various electrostatic models such as the diffuse double layer, basic Stern, triple layer or CD-MUSIC models [1, 3-10]. Most sophisticated models are able to reproduce data for a wide range of experimental conditions but rely on the fitting of a large number of parameters whose physical significance is not always easy to justify. Moreover, the uniqueness of a set of parameters is not always obvious. On the other hand, less sophisticated models rely on the fitting of fewer parameters but often fail to reproduce the data under all of the experimental conditions studied. At present, there is no consensus on which is the "best model" to represent charged surfaces at oxide-water interfaces.

Of all the physico-chemical parameters characterizing the solid/water interface, the zeta potential is particularly important. It is the potential at the supposed slipping plane that 
separates the stationary and mobile phases in tangential flow of the liquid with respect to the surface. For example, in the case of a particle undergoing electrophoresis, because of the electrostatic interactions between the applied electric field and the hydrated counter-ions in the diffuse layer, the interface develops a surface of shear [12]. The electric potential at the slipping plane is of particular interest if we wish to estimate the critical coagulation concentration when studying nanoparticle agglomeration, for example $[5,12,13]$. The zeta potential is also a key parameter for the study of the transport properties of electrically charged materials like oxide and clay minerals [1416]. It usually makes it possible to optimize the parameters of the electrostatic surface complexation models while assimilating the position of the shear-plane to the position of the head end of the diffuse layer $[10,17]$. This interpretation has, however, been challenged by recent studies on titanium dioxide nanoparticles that show that titration data cannot be reproduced together with zeta potential values without having a shearplane position that changes as a function of the ionic strength. Bourikas et al. [9] and Panagiotou et al. [1] have shown that the shear plane position (in log scale) is linearly dependant on the log value of the ionic strength. This physical model leads, however, to a surface representation in which the shear-plane can be as far as $210 \AA$ from the surface at an ionic strength of $10^{-4} \mathrm{M}$ (Figure 32 of [1]), the entire volume between the oxide surface and this shear-plane being considered to be "stagnant". Moreover, this physical representation of the oxide surface rules out any use of the zeta potential as a constraint for surface charge models. The nature of the physical property that causes the separation between the "stagnant" diffuse layer and the "mobile" diffuse layer is, however, not given. Molecular dynamics studies and X-ray measurements on oxide and aluminosilicate surfaces tend to show that diffuse layer water properties (density, mobility, molecule orientation) are very similar to those of bulk water [18-20]. 
Electrophoretic mobility measurements are usually used to determine the zeta potential. However, zeta potential estimations can be erroneous due to the uncertainty concerning the value of the conversion factor used [12]. This could explain the "observed" shift of the shear-plane position as a function of the ionic strength in surface complexation models. Numerous authors [18-26] emphasize that the anomalous surface conductivity of particles might explain the low zeta potential values (in amplitude) determined from electrophoresis compared to values estimated by surface complexation models at the OHP and electrical conductivity measurements. They also state that the lateral motion of adsorbed counterions at the Stern layer must not be disregarded for some materials having a large excess of electrical charge at their surface (like clay minerals or latex suspensions). Little work has been done to characterize the surface conductance due to the Stern layer for titanium dioxide nanoparticles [27]. In addition, the surface conductivity of $\mathrm{TiO}_{2}$ nanoparticles may be strong due to the small size of the elementary particles.

The aim of this work is to study the possible influence of $\mathrm{TiO}_{2}$ nanoparticle surface conductivity on its electrophoretic mobility in the hope that this will lead to zeta potential values in agreement with those predicted by electrostatic surface complexation models (without considering large variations of the distance between the outer boundary of the compact layer and the inner boundary of the diffuse layer). Surface speciation models are needed to calculate the surface conductance of $\mathrm{TiO}_{2}$. For this reason, the model developed recently by Panagiotou et al. [1] and alternative models are critically evaluated in the second chapter of this study. In the third chapter, we discuss the theories used to convert electrophoretic mobility to zeta potential and calculate surface conductance due to the double layer. In the fourth chapter, we describe our modeling 
strategy and use the proposed methodology to estimate the "intrinsic" zeta potential of titanium dioxide $\mathrm{P} 25$ in a $\mathrm{NaCl}$ electrolyte from electrophoresis.

\section{Electrostatic models for titanium oxides}

\subsection{Panagiotou et al. model (2008)}

Panagiotou et al. [1] proposed a Triple Plane Model (TPM, [6]) for the titanium oxide (P25) solid-solution interface in $\mathrm{NaNO}_{3}$ and $\mathrm{KNO}_{3}$ electrolyte solutions. This model is based on a state-of-the-art description of the $\mathrm{TiO}_{2}$ surface properties with regards to protonation-deprotonation processes using the recent ab-initio calculations and DFT developments for this material. Two main surface functional groups were found to be responsible for the surface reactivity:

$$
\begin{aligned}
& \mathrm{Ti}_{2} \mathrm{O}^{-0.57}+\mathrm{H}^{+} \rightleftharpoons \mathrm{Ti}_{2} \mathrm{OH}^{+0.43} \quad \log \mathrm{K}_{1}, \\
& \mathrm{TiO}^{-0.35}+\mathrm{H}^{+} \rightleftharpoons \mathrm{TiOH}^{+0.65} \quad \log \mathrm{K}_{2} .
\end{aligned}
$$

Total surface site density was fixed at a value of 5.6 sites $\mathrm{nm}^{-2}$ obtained from crystallographic considerations. Total surface area was $50 \mathrm{~m}^{2} \mathrm{~g}^{-1}$ according to BET measurements.

The surface ionization model was then combined with a triple plane model, and the predictions were used together with potentiometric titration, microelectrophoresis and streaming potential experiments to describe the electrochemical properties of the $\mathrm{TiO}_{2}$ surface. Both surface sites were considered to behave similarly with a given cation $\left(\mathrm{Na}^{+}\right.$ and $\mathrm{K}^{+}$) or anion $\left(\mathrm{NO}_{3}{ }^{-}\right)$. This simplification enabled the authors to reduce the number of adjustable parameters for their model:

$$
\mathrm{Ti}_{2} \mathrm{O}^{-0.57}+\mathrm{Na}^{+} \rightleftharpoons \mathrm{Ti}_{2} \mathrm{O}^{-0.57}-\mathrm{Na}^{+} \quad \log \mathrm{K}_{\mathrm{Na}}
$$


$\mathrm{TiO}^{-0.35}+\mathrm{Na}^{+} \rightleftharpoons \mathrm{TiO}^{-0.35}-\mathrm{Na}^{+} \quad \log \mathrm{K}_{\mathrm{Na}}$,

$\mathrm{Ti}_{2} \mathrm{OH}^{+0.43}+\mathrm{NO}_{3}{ }^{-} \rightleftharpoons \mathrm{Ti}_{2} \mathrm{OH}^{+0.43}-\mathrm{NO}_{3}{ }^{-} \log \mathrm{K}_{\mathrm{NO} 3}$,

$\mathrm{TiOH}^{+0.65}+\mathrm{NO}_{3}{ }^{-} \rightleftharpoons \mathrm{TiOH}^{+0.65}-\mathrm{NO}_{3}{ }^{-} \log \mathrm{K}_{\mathrm{NO} 3}$.

In the triple plane model, the charge of sorbing cations and anions is not attributed to only one electrostatic plane but is distributed over the three planes $(0,1,2)$, thus adding two additional fitting parameters $\left(\Delta \mathrm{z}_{0}\right.$ and $\Delta \mathrm{z}_{1}$ or $\Delta \mathrm{z}_{1}$ and $\left.\Delta \mathrm{z}_{2}\right)$ for each sorbed species at each surface site (Fig. 1). Again, both surface sites were considered to behave similarly with a given cation or anion.

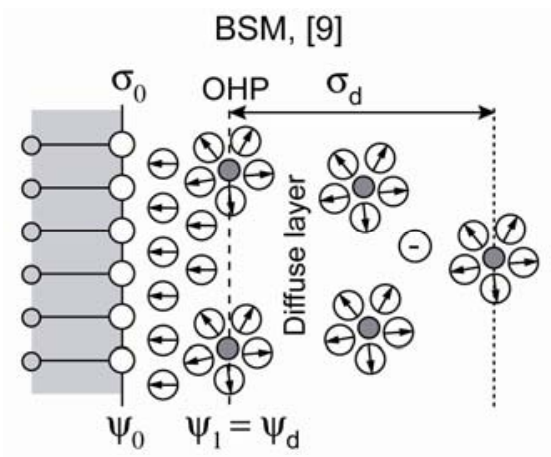
BSM, our study
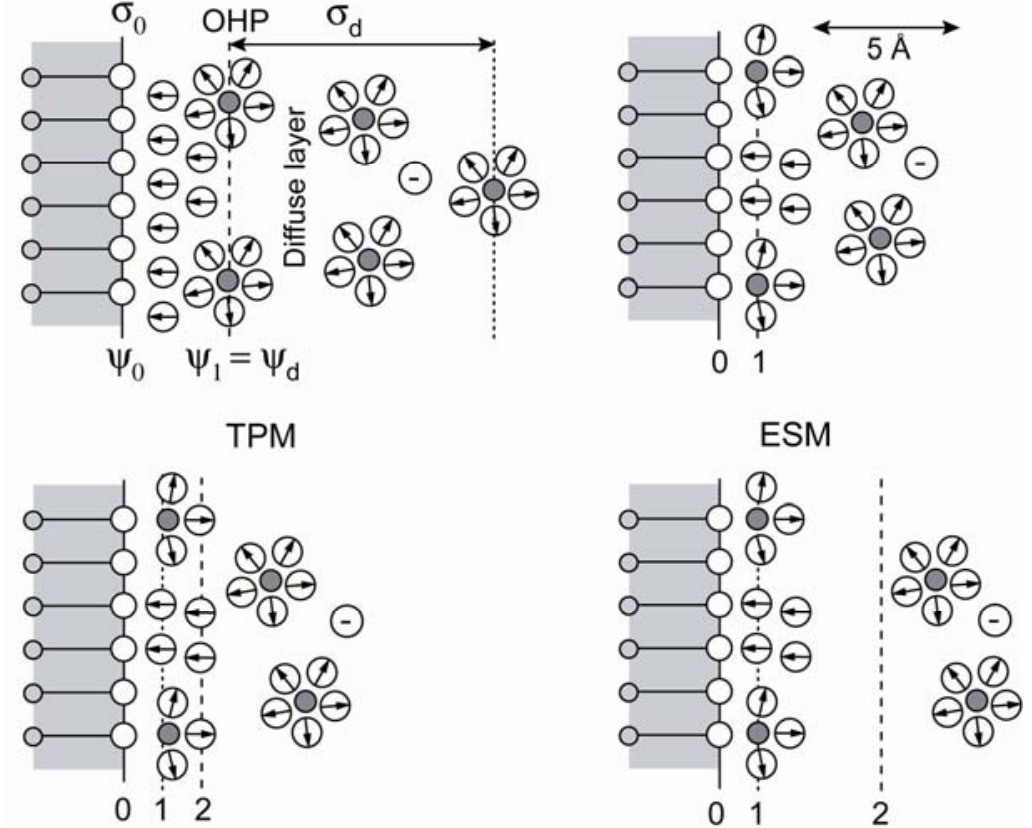

Fig. 1. Schematic drawing of the basic Stern model of Bourikas et al. [9], our basic Stern model, the triple plane model of Panagiotou et al. [1], and our extended Stern model for a negatively charged surface of titanium dioxide. At a given picture, from left to right: metal ions, surface hydroxyls, primary and secondary water layers, compact layer, diffuse layer. 
The parameters of this model are given for a $\mathrm{NaNO}_{3}$ electrolyte background in Table 1 . We reproduced their model using PHREEQC v2.17 [28]. We were not able to reproduce their titration curves using the parameters in the reference publication. The tabulated protonation/deprotonation constants $\left(\log \mathrm{K}_{1}\right.$ and $\left.\log \mathrm{K}_{2}\right)$ had to be changed slightly in order to obtain results in full agreement with the data. Hereafter, we refer to this modified model as "Reference model" (Table 1). Surface charge predictions are given in Fig. 2 together with surface potential at the 2-plane, which is considered to be the head end of the diffuse layer. This parameter can be compared to the zeta potential.
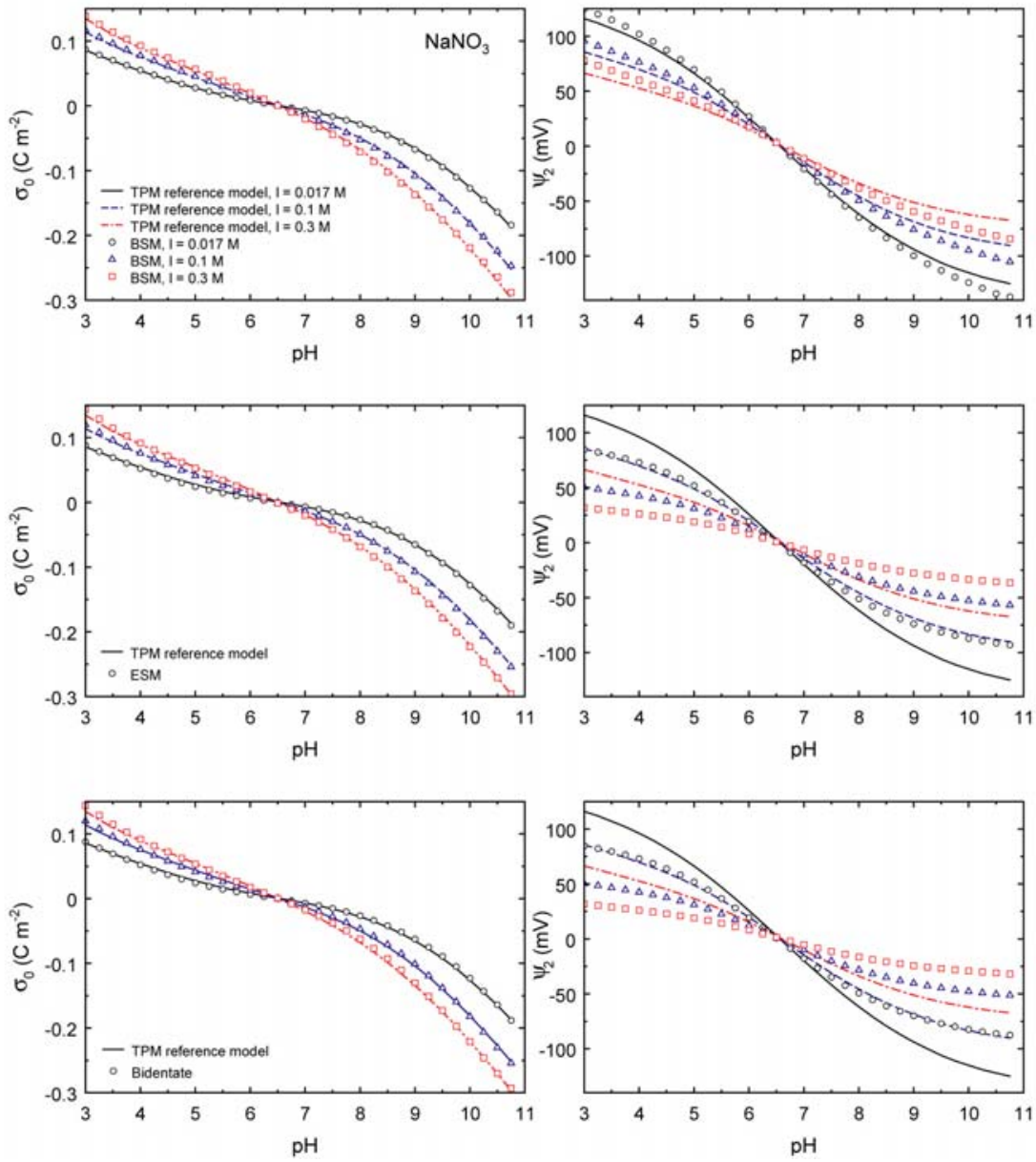

Fig. 2. $\mathrm{TiO}_{2}$ surface charge and potential at the head end of the diffuse layer predicted by different surface complexation models at three ionic strengths $I$ in $\mathrm{NaNO}_{3}$. Lines depict the reference model (TPM) results while symbols depict the results of alternative models (BSM, ESM, Bidentate, Table 1). 
Panagiotou et al. [1] reported zeta potential values far below the potential values of the 2-plane (in absolute value). They interpreted this to be a consequence of a shift of the shear plane (where the zeta potential is located) from this 2-plane. While calculating the distance $d$ from the 2-plane to the shear plane, they found a log-log linear relationship between the ionic strength $I$ (in $\mathrm{M}$ ) and $d$ (in $\mathrm{nm}$ ):

$\log d=-0.5115 \log I-0.7229$.

\subsection{Alternative models}

While the data of Panagiotou et al. [1] could be very well reproduced by their TPM model, it could also be reproduced with the simpler Basic Stern Model (BSM). The BSM parameters (Table 1) give surface charge results nearly identical to those of the TPM reference model in $\mathrm{NaNO}_{3}$ electrolyte (Fig. 2) although the BSM requires only five fitting parameters instead of ten for TPM. This raises the question of the uniqueness of the TPM parameter set. In principle, this problem can be overcome by fitting a large range of data obtained under the same experimental conditions but testing different electrolyte types. Panagiotou et al. [1] provided titration data in a $\mathrm{KNO}_{3}$ electrolyte background and were able to fit them adequately only by attributing an association constant $\left(\log \mathrm{K}_{\mathrm{K}}=-1.1\right)$ and a charge distribution $\left(\Delta \mathrm{z}_{1 \mathrm{~K}}=0, \Delta \mathrm{z}_{2 \mathrm{~K}}=1\right)$ for $\mathrm{K}^{+}$at the surface, while keeping the other parameters constant. A good agreement can also be obtained with the BSM model (Fig. 3) adding only an association constant $\left(\log \mathrm{K}_{\mathrm{K}}=\right.$ 1.7) for $\mathrm{K}^{+}$. There is a discrepancy between the titration predictions of the two models at $0.017 \mathrm{M}$, but the differences increase with salinity, and are therefore greater and significant for a salinity of $0.3 \mathrm{M}$ and $\mathrm{pH}>9.5$. Consequently, the addition of five fitting parameters for the triple plane model relies on a very restricted subset of experimental data points. 

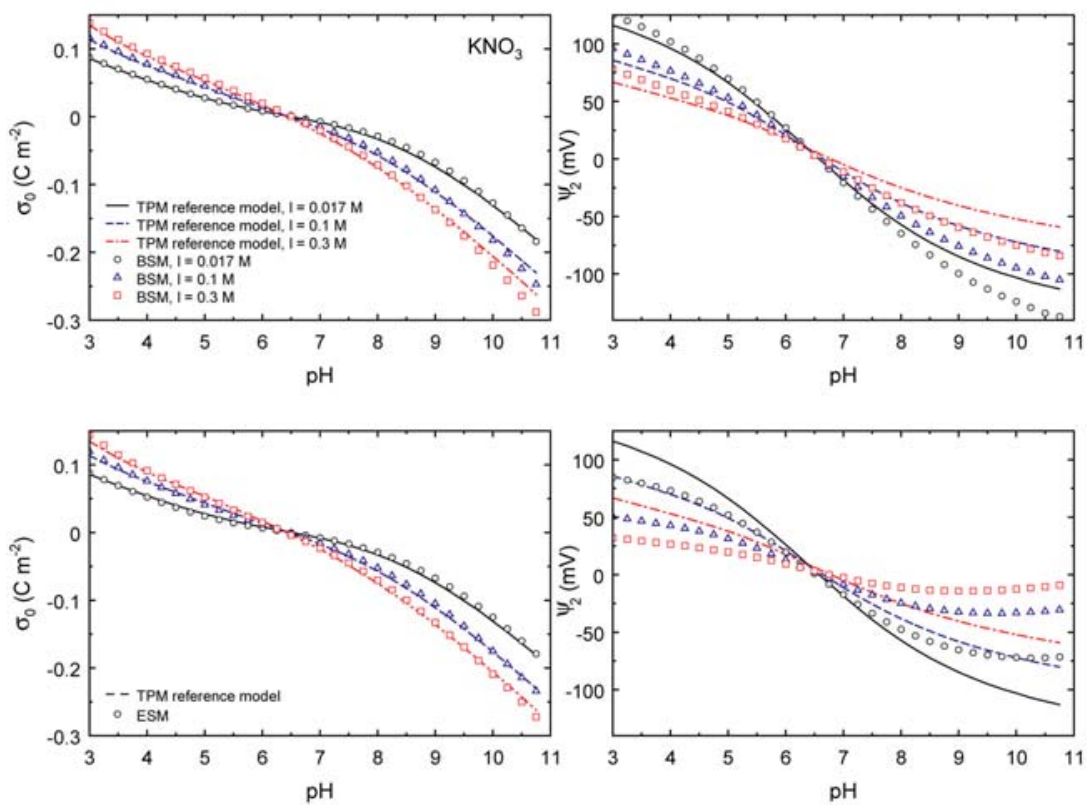

Fig. 3. $\mathrm{TiO}_{2}$ surface properties predicted by different surface complexation models at three ionic strengths in $\mathrm{KNO}_{3}$. Lines depict the TPM reference model results while symbols depict the results of alternative models (Table 1).

The right sides of Fig. 2 and Fig. 3 show that the choice of a given model influences the prediction of the electrical potential at the head end of the diffuse layer. For these two models, however, predicted potentials are much higher in amplitude than reported zeta potentials from electrophoresis [3], corroborating the hypothesis of a shear plane located in the diffuse layer.

As an alternative model, an Extended Stern Model (ESM) can reproduce perfectly the reference TPM for surface charge but diminishs the potential at the head end of the diffuse layer. One set of this model's parameters, amongst those tested successfully, is given in Table 1. Corresponding titration and potential curves are shown in Fig. 2 and Fig. 3 for $\mathrm{NaNO}_{3}$ and $\mathrm{KNO}_{3}$ electrolyte backgrounds, respectively.

According to Panagiotou et al. [1], the high capacitance values of the reference TPM are in agreement with theoretical and experimental studies concerning the location of the 
first two water overlayers and the electrolyte counterions at the rutile surface, taken here as a good analogue of the anatase surface [29-34]. Predota and Vlcek and Predota et al. $[31,33]$ showed that the first hydration layer at the rutile surface is $\sim 1.8 \AA$ from the surface terminal oxygen atoms and that $\mathrm{Na}^{+}$cations are located at $\sim 1-1.8 \AA$. These distances are in agreement with the capacitance value $C_{1}=3.2 \mathrm{~F} \mathrm{~m}^{-2}$ that locates 1-plane at $d_{1}=1.7 \AA$ from the 0 -plane, while considering the following equation with the mean relative dielectric constant, $\varepsilon_{r, 1}$, equal to 60 ( $\varepsilon_{0}$ is the dielectric constant of the vacuum, $\left.8.85 \times 10^{-12} \mathrm{C} \mathrm{V}^{-1} \mathrm{~m}^{-1}\right):$ $C_{1(2)}=\frac{\varepsilon_{0} \varepsilon_{r, 1(2)}}{d_{1(2)}}$

where $C_{2}, d_{2}$ and $\varepsilon_{r, 2}$ are the capacitance, distance and the mean relative dielectric constant between the 1- and 2-planes, respectively. The proposed ESM model has a lower capacitance $C_{1}=2.5 \mathrm{~F} \mathrm{~m}^{-2}$. It could therefore be considered to not be in agreement with above results. However, parameter $\varepsilon_{r, 1}$ is ill-defined. Taking a value of $\varepsilon_{r, 1}=47$ enables us to arrive at the same distance $d_{1}$ with the ESM model. Consequently, available data at the molecular level combined with titration data cannot be used to determine which is the best representative model since both $\varepsilon_{r, 1}$ values are reasonable [35]. We were, however, not able to achieve a good fit of titration data with models having a $C_{1}$ value lower than $2.5 \mathrm{~F} \mathrm{~m}^{-2}$. This seems to confirm the presence of a layer with a high capacitance and $\mathrm{Na}$ sorption close to the surface. On the contrary, $C_{2}$ could be set at a value as low as $1 \mathrm{~F} \mathrm{~m}^{-2}$ in the ESM, in marked contrast with the $4.2 \mathrm{~F} \mathrm{~m}^{-2}$ value of the reference TPM. The position of the second plane is also subject to discussion. Panagiotou et al. [1] considered that the second plane ends the compact layer at a distance of $3.4 \AA$ from the surface. However, molecular dynamics calculations show significant water density oscillations up to $12 \AA$ from the surface associated with 
continuous viscosity changes [33]. As a consequence, the choice of a precise location for the second plane cannot be easily justified. Moreover, the calculation of the capacitance value for the region between the 1- and 2-planes relies heavily on the modeler's choice for $\varepsilon_{r, 2}$.

Theoretical calculations indicate that the greatest portion of sorbed $\mathrm{Na}^{+}$forms bidentate complexes. We tried to roughly incorporate this information by considering the following equilibria in another alternative model (the "Bidentate" model in Table 1):

$2 \mathrm{Ti}_{2} \mathrm{O}^{-0.57}+\mathrm{Na}^{+} \rightleftharpoons\left(\mathrm{Ti}_{2} \mathrm{O}^{-0.57}\right)_{2}-\mathrm{Na}^{+} \log \mathrm{K}_{\mathrm{Na}}$,

$2 \mathrm{TiO}^{-0.35}+\mathrm{Na}^{+} \rightleftharpoons\left(\mathrm{TiO}^{-0.35}\right)_{2}-\mathrm{Na}^{+} \quad \log \mathrm{K}_{\mathrm{Na}}$.

The charge of counter $\mathrm{Na}^{+}$was attributed partly to the 0-plane and partly to the 1-plane, since $\mathrm{Na}^{+}$was also shown to be partly dehydrated at the surface and engaged in inner sphere complexes [34]. Fig. 2 again shows that this model can match almost perfectly the reference TPM titration predictions. Note also that, depending on the chosen surface complexation model, i.e. TPM, BSM, ESM, or Bidentate, there may be different locations and then definitions of the "stagnant layer" (which is not necessarily a monolayer of sorbed counterions). For example, in the case of a $\mathrm{NaNO}_{3}$ electrolyte, the stagnant layer is located between 1 and 2-planes for TPM, at the 1-plane for BSM, at the 1-plane for ESM and between the 0 and 1-planes for Bidentate.

\subsection{Implications for mapping the "titanium dioxidelelectrolyte solution" interface}

This analysis shows that titration data combined with surface complexation models such as TPM or ESM cannot yield a unique and unambiguous set of interfacial parameters. Theoretical calculations and modeling at the molecular scale can help us validate the model likelihood but uncertainties remain. 
This suggests that the relationship observed between the position of the shear plane and the ionic strength (Eq. (7)) is model dependant. Fig. 2 and Fig. 3 show that the reference TPM and the BSM predict nearly identical potentials at the head end of the diffuse layer, in agreement with the fact that the reference TPM is an improvement on the BSM published earlier by Bourikas et al. [9]. However, the proposed ESM and "Bidentate" models predict lower potentials (in absolute value) than the reference model. Predicted potentials remain, however, higher in absolute value than commonly reported zeta potential from electrophoresis. Consequently, the question of the position of the shear plane in relation to the head end of the diffuse layer remains.

Zeta potential calculations from electrophoresis are also model-dependant. In the following chapter, several models to convert electrophoretic measurements to zeta potentials are briefly reviewed.

\section{From the electrophoretic mobility to the zeta potential}

\subsection{Electrokinetic theories}

The most well-known and widely used theory of electrophoresis was developed by von Smoluchowski [36, 37]. He studied the movement of the liquid adjacent to a flat, electrically charged surface under the influence of an electric field applied parallel to the interface. Von Smoluchowski [36] used the Stokes equation and calculated the electrical (using Poisson equation) and viscous forces on an element of volume of the liquid to express the electrophoretic mobility as a function of the zeta potential. The von Smoluchowski equation linearly relates the electrophoretic mobility $\mu_{e}$ (in $\mathrm{m}^{2} \mathrm{~s}^{-1} \mathrm{~V}^{-}$

$\left.{ }^{1}\right)$ to the electrical potential at the shear plane $(\zeta$, in $\mathrm{V})$ :

$$
\mu_{e}=\frac{\varepsilon}{\eta} \zeta
$$


where $\eta$ is the dynamic viscosity (in Pa s; $\eta=0.895 \times 10^{-3}$ Pa s at $T=298 \mathrm{~K}$ ) and $\varepsilon$ the dielectric permittivity of water $\left(\varepsilon=\varepsilon_{0} \varepsilon_{r}=78.3 \times 8.85 \times 10^{-12} \mathrm{~F} \mathrm{~m}^{-1}\right.$ at $\left.T=298 \mathrm{~K}\right)$. The von Smoluchowski equation is valid only if the thickness of the diffuse layer is insignificant compared to the size of the particle, i.e. for thin double layer, $\kappa a>>1$, where $\kappa$ is the inverse of the Debye length (in $\mathrm{m}^{-1}$ ) and $a$ the particle radius (in $\mathrm{m}$ ). The inverse of the Debye length is given by:

$$
\begin{gathered}
\kappa=\sqrt{\frac{F^{2} \sum_{i} z_{i}^{2} c_{i}^{b}}{\varepsilon R T}}, \\
\kappa=\sqrt{\frac{F^{2} \times 2 \times I}{\varepsilon R T}},
\end{gathered}
$$

where $F$ is the Faraday constant $\left(96485 \mathrm{C} \mathrm{mol}^{-1}\right), R$ the gas constant $\left(8.314 \mathrm{~J} \mathrm{~mol}^{-1} \mathrm{~K}^{-1}\right)$, $c_{i}$ the ions concentrations (in mol $\mathrm{m}^{-3}$ ), $z_{i}$ their valency, and $I$ the ionic strength. The symbol " $b$ " refers to the bulk ions.

For small spherical particles having a thick double layer, $\kappa a<<1$, the applied electric field is not influenced by the presence of the particle and the effect of the retardation force due to the double layer on the migration of the particle is negligible. Hückel [38] considered that the main retardation force is the frictional resistance of the medium. He supposed that the electrical conductivity of the particle is the same as that of the surrounding medium. Therefore, the electric field is not distorted by the particle. He wrote the following equation, which is valid for $\kappa a<<1$ :

$\mu_{e}=\frac{2 \varepsilon}{3 \eta} \zeta$

Henry $[39,40]$ revisited Hückel's theory by considering that the conductivity of the particle is different from that of the surrounding medium. In this case, the applied electric field will be distorted so that the isopotential values can be around the particle 
surface. According to Henry [40], the particle's conductivity alters the shape of the potential distribution of the applied field in the liquid, modifies the fluid motion within the electrical double layer, and therefore changes the stresses of the fluid exerted on the particle. Consequently, this conductivity leads to the mutual distortion of the applied field and the field of the double layer, and hence slows the electrophoretic motion. For spherical particles with arbitrary double-layer thickness, Henry [40] wrote:

$$
\begin{aligned}
& \mu_{e}=\frac{2 \varepsilon}{3 \eta} F\left(\kappa a, K_{p}, K_{s}\right) \zeta, \\
& F\left(\kappa a, K_{p}, K_{s}\right)=1+2 \lambda[f(\kappa a)-1], \\
& \lambda=\frac{1-K_{p}-2 K_{s}}{2+K_{p}+2 K_{s}}, \\
& K_{p}=\frac{\sigma_{p}}{\sigma_{b}}, \\
& K_{s}=\frac{\sigma_{s}}{\sigma_{b}}=\frac{\Sigma_{s}}{a \sigma_{b}}, \\
& f(\kappa a)=1+\frac{(\kappa a)^{2}}{16}-\frac{5(\kappa a)^{3}}{48}-\frac{(\kappa a)^{4}}{96}+\frac{(\kappa a)^{5}}{96} \\
& -\frac{11}{96} \exp (\kappa a) \int_{\infty}^{\kappa a} \frac{\exp (-t)}{t} d t, \text { for } \kappa a<1, \\
& f(\kappa a)=\frac{3}{2}-\frac{9}{2 \kappa a}+\frac{75}{2 \kappa^{2} a^{2}}-\frac{330}{\kappa^{3} a^{3}}, \text { for } \kappa a>1,
\end{aligned}
$$

where $\sigma$ is the electrical conductivity (in $\mathrm{S} \mathrm{m}^{-1}$ ), $\Sigma$ the surface conductance of the electrical double layer, the subscripts " $p$ ", " $s "$, " $b$ " corresponding, respectively, to the particle "interior", the particle surface and the surrounding medium (the bulk electrolyte). The surface conductance expresses the excess of electrical conductivity at the solid surface compared to that of the bulk electrolyte. $K_{s}$ corresponds to the well- 
known "Dukhin number", Du (see [18,41] and [42] for more details). According to Eqs. (15) to (17) and by replacing $K_{s}$ with Du, we obtain:

$$
\mu_{e}=\frac{2 \varepsilon}{3 \eta}\left\{1+2\left(\frac{1-K_{p}-2 \mathrm{Du}}{2+K_{p}+2 \mathrm{Du}}\right)[f(\kappa a)-1]\right\} \zeta .
$$

In the absence of surface conductance and in the case of an insulating particle, Henry's theory leads to von Smoluchowski's equation for large $\kappa a$ values $(f(\kappa a)=1.5)$ and Hückel's equation for $\kappa a<<1$ (thick double layer, $f(\kappa a)=1$ ). For $\kappa a>>1, f(\kappa a)=1.5$, and Eq. (22) reduces to:

$$
\mu_{e}=\frac{2 \varepsilon}{3 \eta}\left(1+\frac{1-K_{p}-2 \mathrm{Du}}{2+K_{p}+2 \mathrm{Du}}\right) \zeta .
$$

In the case of insulating particles, $K_{p}=0$, and Eq. (23) corresponds to O'Brien's formula [43] within the limit of a DC applied electric field and disregarding the inertial term in his theory. O'Brien [43] developed a complete picture of the frequency dependent dielectric response of a dilute suspension of spheres with thin double layers. Note that all of the equations presented here, except Smoluchowski's equation, consider a DebyeHückel ionic atmosphere, i.e. that electric potential in the diffuse layer follows a DebyeHückel distribution. Consequently, the analytical equations that we use to estimate the zeta potential from the electrophoretic mobility are valid for low zeta potentials $(|\zeta| \leq$ $25.7 \mathrm{mV}$ in the case of $1: 1$ electrolyte at $T=298 \mathrm{~K}$ ), but they can still be applied for zeta potentials of greater amplitude [12].

In addition, Eqs. (11) to (23) do not consider spheroidal particles, particle volume fraction, polydispersity of the sample, i.e. agglomerates of different sizes, and diffuse layer overlapping. Several electrokinetic models make it possible to estimate surface conductance for spheroidal particles (for example, [44]), consider polydispersivity of the sample and nanoparticles agglomeration [45], and diffuse layer overlapping [46]. 
Moreover, Mangelsdorf and White's numerical model, which takes into account particle size effects and the adsorption of ions and their mobility in the inner part of the EDL [21], can be more accurate than the analytical solutions we use, especially at low ionic strength and at $\mathrm{pH}$ values far from the PZC where the amplitude of the surface electric potential is high.

However, the electrical conductivity of the particle "interior" $\sigma_{p}$ can be determined using the so-called differential self-consistent model [47, 48]. This model considers small contiguity between the particles and allows the determination of the electrical conductivity of the agglomerate corresponding to the final concentration of inclusions (here the elementary nanoparticles of conductivity $\sigma_{e}$ ) by addition of infinitesimal portions of inclusions:

$\int_{\sigma_{b}}^{\sigma_{p}} \frac{\sigma_{e}+2 \sigma}{3 \sigma\left(\sigma_{e}-\sigma\right)} d \sigma=\int_{0}^{1-\phi} \frac{d \Omega}{1-\Omega}$

where $\phi$ is the intra-aggregate porosity, $\Omega=v /(v+V)$ is the volume fraction of the elementary nanoparticles in the agglomerate with $v$ and $V$ the total volume (in $\mathrm{m}^{-3}$ ) of elementary particles and of water, respectively. By integrating Eq. (24), we obtain:

$$
\frac{\sigma_{p}-\sigma_{e}}{\sigma_{b}-\sigma_{e}}\left(\frac{\sigma_{b}}{\sigma_{p}}\right)^{D}=\phi,
$$

where $D=1 / 3$ in the case of spherical elementary particles. Eq. (25) has been generalized to non-spherical particles, but it is not very practical because it is an equation of the form $\sigma_{p}=f\left(D, \phi, \sigma_{b}, \sigma_{e}, \sigma_{p}\right)$. Revil [48] found an analytical solution of Eq. (25) by considering $D=1 / 2$ for disk-shaped particles:

$$
\sigma_{p}=\frac{\sigma_{b}}{F}\left[F \Theta+\frac{1}{2}(1-\Theta)\left(1-\Theta+\sqrt{(1-\Theta)^{2}+4 F \Theta}\right)\right]
$$


$\Theta=\frac{\sigma_{e}}{\sigma_{b}}=\frac{2 \Sigma_{s}}{a_{e} \sigma_{b}}$

$F=\phi^{-2}$

According to Revil [48], $D=1 / 2$ corresponds to a particle's shape usually found in most porous media. In addition, following the approach of [45], the electrophoretic mobility due to the polydispersity of the sample, $\bar{\mu}_{e}$, i.e. to agglomerates possessing different sizes, can be calculated by:

$\bar{\mu}_{e}=\frac{\sum_{i=1}^{N} \mu_{e}^{i} f\left(a_{i}\right) a_{i}^{3} \Delta a_{i}}{\sum_{i=1}^{N} f\left(a_{i}\right) a_{i}^{3} \Delta a_{i}}$,

where $N$ is the number of different radii, $f\left(a_{i}\right)$ represents the discretized version of the Particle Size Distribution (PSD), $\Delta a_{i}$ the radius intervals, and $\mu_{e}^{i}$ the electrophoretic mobility of agglomerates with radius $a_{i} \pm \Delta a_{i} / 2$. According to Eq. (29), the electrophoretic mobility of the polydisperse system is the volume average of the mobilities of particles with different sizes in the distribution.

Henry [40] and O'Brien [43] considered that only the counterions in the diffuse layer are responsible for the surface conductivity. They did not consider the influence of the Stern layer on particle surface conductivity [18-23]. According to these authors, the zeta potential of (electrically) charged suspensions like polystyrene lattices, determined from electrophoresis, are lower in amplitude than the zeta potential values estimated from electrical conductivity measurements. In the case of electrophoresis, these authors assume that the lateral movement of ions at the Stern layer in response to the applied electric field can explain such discrepancy. The presence of mobile counterions at the Stern layer and in the diffuse layer lowers the amplitude of zeta potentials inferred from 
mobility measurements and raises those from conductivity measurements, compared to the zeta potentials that correspond to the intrinsic particle charge.

The "anomalous" surface conductance linked to the Stern layer, i.e. to ions below the shear plane, can be determined for oxide minerals using electrical conductivity measurements $[25,27,42,49]$ or a surface complexation model like a Triple Layer Model (TLM, [15, 50]) where the associated equilibrium sorption constants are calibrated by titration experiments. Surface complexation models calculate the excess of counterions at the interface and thereby make it possible to estimate the (specific) surface conductance of the particle $[50,51]$.

\subsection{Determination of the surface conductance}

3.2.1. The diffuse layer surface conductance

The surface conductance of the Electrical Double Layer (EDL) is the enhanced conductivity due to the presence of a double layer at the particle surface ([40, 49-51]; see Fig. 4). We consider here the surface conductance due only to the presence of the diffuse layer at the particle surface. In the following chapter, we will consider the influence of the Stern layer on the surface conductance. 


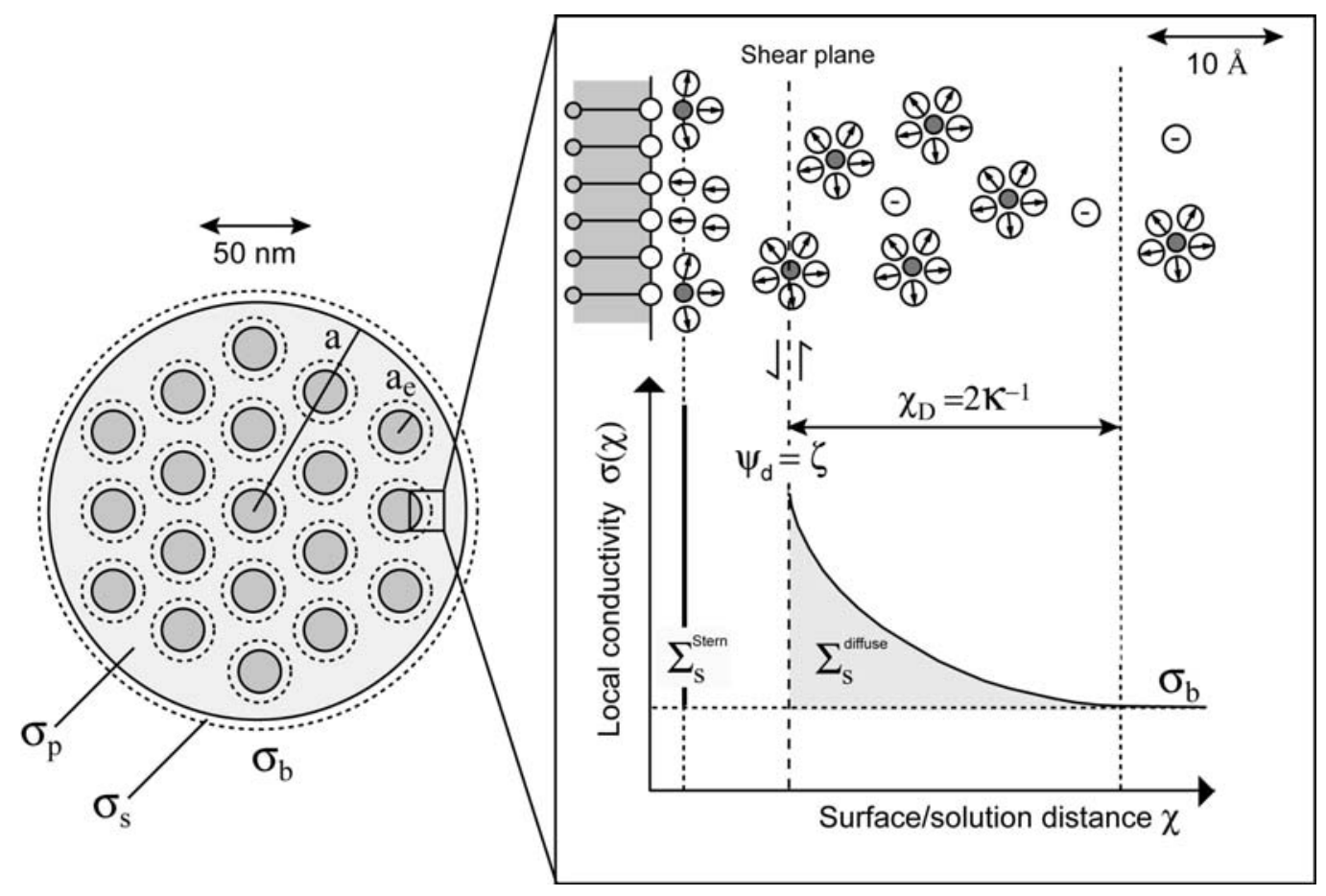

Fig. 4. Schematic representation of the electro-chemical properties of a suspension of spherical oxide nanoparticles. The particle has a local excess of electrical conductivity at its interface $\sigma(\chi)$. The surface conductance $\Sigma_{s}$ is estimated by integrating $\sigma(\chi)-\sigma_{b}$ over the thickness of the Stern and diffuse layers.

According to Revil and Glover [51], the surface conductance $\Sigma_{s}$ (in S) can be described by the individual specific surface conductance of each ion in the diffuse layer, $\Sigma_{i}^{s}$,

$$
\Sigma_{s}=\sum_{i} e z_{i} \Sigma_{i}^{s}
$$

The total surface conductance $\Sigma_{s}$ is made up of an electro-migration, $\Sigma_{s}^{e}$, and an electro-osmotic surface conductance, $\Sigma_{s}^{o s}$,

$$
\Sigma_{s}=\Sigma_{s}^{e}+\Sigma_{s}^{o s}
$$

The electro-migration surface conductance is due to the excess of Ohmic conductivity in the EDL [15], 
$\Sigma_{s}^{e}=\int_{0}^{\chi_{D}}\left[\sigma(\chi)-\sigma_{b}\right] d \chi$

where $\chi$ represents the surface/solution distance in $\mathrm{m}$ and $\chi_{D}$ is the total thickness of the diffuse layer (usually, $\chi_{D}=2 \kappa^{-1}$ ). The parameters $\sigma(\chi)$ and $\sigma_{b}$ are the electrical conductivity at the solid/solution interface and in the bulk pore water defined, respectively, by:

$$
\begin{aligned}
& \sigma(\chi)=\sum_{i} F z_{i} \beta_{i}^{s} c_{i}^{s}(\chi), \\
& \sigma_{b}=\sum_{i} F z_{i} \beta_{i}^{b} c_{i}^{b},
\end{aligned}
$$

where $\beta_{i}^{s, b}$ is the ion mobility (in $\mathrm{m}^{2} \mathrm{~s}^{-1} \mathrm{~V}^{-1}$ ) at the particle surface and in the bulk pore water. The electrical conductivity of the solution due to electro-migration is given by an equivalent Ohm's law determined using the generalized Nernst-Planck equations and the electrochemical potential equations for the ion species $[14,52]$ (electro-osmosis is neglected). The local electrical conductivity $\sigma(\chi)$ is given by analogy with the free electrolyte conductivity ([51]). By incorporating Eqs. (33) and (34) in Eq. (32), we obtain:

$$
\Sigma_{s}^{e}=\int_{0}^{\chi_{D}} \sum_{i} F z_{i}\left[\beta_{i}^{s} c_{i}^{s}(\chi)-\beta_{i}^{b} c_{i}^{b}\right] d \chi
$$

According to Eq. (35), by considering the same ion mobility at the interface (diffuse layer here) and in the bulk pore water, i.e. $\beta_{i}^{s}=\beta_{i}^{b}=\beta_{i}$, we can determine $\Sigma_{s}^{e}[15,53]$ :

$$
\begin{aligned}
& \Sigma_{s}^{e}=F \sum_{i} z_{i} \beta_{i} \int_{0}^{\chi_{D}}\left[c_{i}^{s}(\chi)-c_{i}^{b}\right] d \chi, \\
& \Sigma_{s}^{e}=F \sum_{i} z_{i} \beta_{i} c_{i}^{b} \int_{0}^{\chi_{D}}\left\{\exp \left[-\frac{ \pm z_{i} F \psi(\chi)}{R T}\right]-1\right\} d \chi, \\
& \psi(\chi)=\psi_{d} \exp (-\kappa \chi),
\end{aligned}
$$


where $\psi_{d}$ is the electric potential at the head end of the diffuse layer. The term \pm corresponds to the sign of the electrical charge associated with the species $i$ ("+" for cations and "-" for anions).

It is relatively easy to find an analytical solution for the ion contribution to the surface conductance using Eqs. (30), (37)-(38) and linearizing the exponential function of the Boltzmann distribution ([51] and Eqs. (191) to (194) of [54]):

$$
\begin{aligned}
& \Sigma_{s}^{e} \approx 2 \kappa^{-1} F \sum_{i} z_{i} \beta_{i} c_{i}^{b}\left[\exp \left(-\frac{ \pm z_{i} F \psi_{d}}{2 R T}\right)-1\right], \\
& \Sigma_{i}^{e} \approx 2 \kappa^{-1} \beta_{i} \operatorname{Na}_{i}^{b}\left[\exp \left(-\frac{ \pm z_{i} F \psi_{d}}{2 R T}\right)-1\right],
\end{aligned}
$$

where $\mathrm{Na}$ is the Avogadro Number $\left(6.022 \times 10^{23}\right.$ sites $\left.\mathrm{mol}^{-1}\right)$ and by considering a diffuse layer having a thickness of $\chi_{D}=2 \kappa^{-1}$.

At the surface of the titanium dioxide particle (for conditions other than the IEP and for low ionic strength, typically $\leq 0.01 \mathrm{M}$ for oxide minerals, [10]), counter-ions are predominant in the diffuse layer. When an electric field is applied, it results in a solvent convection and, consequently, a surplus conductivity called electro-osmotic conductivity. The electro-osmotic contribution to the surface conductance is described by [51]:

$$
\begin{aligned}
& \Sigma_{s}^{o s}=\int_{0}^{\chi_{D}} \rho(\chi) \beta_{o s}(\chi) d \chi, \\
& \Sigma_{s}^{o s}=\sum_{i} e z_{i} \Sigma_{i}^{o s}, \\
& \rho(\chi)=\sum_{i} F( \pm 1) z_{i} c_{i}^{s}(\chi), \\
& \beta_{o s}(\chi)=\frac{\varepsilon}{\eta}\left[\psi(\chi)-\psi_{d}\right],
\end{aligned}
$$


where $\beta_{o s}$ is the electro-osmotic mobility (in $\mathrm{m}^{2} \mathrm{~s}^{-1} \mathrm{~V}^{-1}$ ) and $\rho$ the volume charge density in the diffuse layer (in $\mathrm{C} \mathrm{m}^{-3}$ ). According to Bikerman [55]:

$$
\Sigma_{s}^{o s} \approx \frac{4 \varepsilon R T}{\eta} \kappa^{-1} \mathrm{Na} \sum_{i} c_{i}^{b}\left[\exp \left(-\frac{ \pm z_{i} F \psi_{d}}{2 R T}\right)-1\right] \text {. }
$$

The ion contribution of the electro-osmotic surface conductance is determined using Eqs. (42) and (45):

$$
\Sigma_{i}^{o s} \approx \frac{4 \varepsilon R T}{\eta e z_{i}} \kappa^{-1} \mathrm{Na} c_{i}^{b}\left[\exp \left(-\frac{ \pm z_{i} F \psi_{d}}{2 R T}\right)-1\right] .
$$

By combining Eqs. (40) and (46), the total ion contribution to the surface conductance is given by:

$$
\begin{aligned}
& \Sigma_{i}^{s}=2 \kappa^{-1} B_{i} \operatorname{Na} c_{i}^{b}\left[\exp \left(-\frac{ \pm z_{i} F \psi_{d}}{2 R T}\right)-1\right] \\
& B_{i}=\beta_{i}+\frac{2 \varepsilon R T}{\eta e z_{i}} .
\end{aligned}
$$

In Eqs. (47) and (48), we have assumed that the ion mobilities are the same in the bulk electrolyte and in the diffuse layer. These equations correspond those of Bikerman [55] for characterizing the ion contribution to the surface conductance of the particle (due to the applied electric field). In his approach, the mobile counterions and coions in the diffuse layer are only responsible for the surface conductance. Moreover, according to Eq. (48), the ionic electro-osmotic contribution to the surface conductance must not be neglected. For example, for a $\mathrm{NaCl}$ solution and at $T=298 \mathrm{~K}$, the $\mathrm{Na}^{+}$and $\mathrm{Cl}^{-}$ion mobility values in the bulk electrolyte are $5.17 \times 10^{-8}$ and $7.89 \times 10^{-8} \mathrm{~m}^{2} \mathrm{~s}^{-1} \mathrm{~V}^{-1}$, respectively [15]. The second term in Eq. (48), for $z_{i}=1, \varepsilon=78.3 \times 8.85 \times 10^{-12} \mathrm{~F} \mathrm{~m}^{-1}, \eta=$ $0.895 \times 10^{-3} \mathrm{~Pa} \mathrm{~s}, F=96485 \mathrm{C} \mathrm{mol}^{-1}, R=8.314 \mathrm{~J} \mathrm{~mol}^{-1} \mathrm{~K}^{-1}$, and $T=298 \mathrm{~K}$, is $\sim 3.98 \times 10^{-}$ ${ }^{8} \mathrm{~m}^{2} \mathrm{~s}^{-1} \mathrm{~V}^{-1}$, which is of the same order of magnitude as the first term. 
For a binary symmetric electrolyte, $z_{+}=z_{-}=z$, and the surface conductance is determined using Eqs. (30) and (47):

$\Sigma_{s}=4 F z \kappa^{-1} c^{b} B\left(\cosh \frac{F z \psi_{d}}{2 R T}-1\right)$

assuming that

$B_{(+)}=B_{(+)}=B$

and

$c_{(+)}^{b}=c_{(-)}^{b}=c^{b}$.

Eq. (49) assumes that both anions and cations have the same mobility. By using Eqs.

(19), (34), (49), and the Nernst-Einstein relationship for ion diffusivity,

$D_{i}=\frac{R T \beta_{i}}{F z}$,

we obtain Bikerman's equation $[25,49,55]$ :

$\mathrm{Du}=\frac{2}{\kappa a}\left[\cosh \left(\frac{F z \psi_{d}}{2 R T}\right)-1\right]\left[1+\frac{2 \varepsilon}{\eta D}\left(\frac{R T}{F z}\right)^{2}\right]$.

In Eq. (53), the influence of $\mathrm{pH}$ on surface conductivity is not taken into account. Taking into consideration the presence of $\mathrm{H}^{+}$and $\mathrm{OH}^{-}$ions, we obtain the following equation for surface conductance, according to Eqs. (30), (47), and for a binary symmetric background electrolyte like $\mathrm{NaCl}$ or $\mathrm{KCl}$ [50]:

$$
\begin{aligned}
& \Sigma_{s}=2 \kappa^{-1} F z\left\{\left(c_{(+)}^{b} B_{(+)}+1000 \times 10^{-\mathrm{pH}} B_{\mathrm{H}+}\right)\left[\exp \left(\frac{-F z \psi_{d}}{2 R T}\right)-1\right]\right. \\
& \left.+\left(c_{(-)}^{b} B_{(-)}+1000 \times 10^{\mathrm{pH}-\mathrm{p} K_{f}} B_{\mathrm{OH}-}\right)\left[\exp \left(\frac{F z \psi_{d}}{2 R T}\right)-1\right]\right\},
\end{aligned}
$$

where $\mathrm{p} K_{f}$ is the negative $\log$ of the dissociation constant of water (14 at $\left.T=298 \mathrm{~K}\right)$. 


\subsubsection{The Stern layer and total surface conductance}

For some highly-charged minerals like clays, the contribution of the compact Stern layer to surface conductivity must not be neglected [53]. However, it has not been extensively studied for titanium dioxide nanoparticles. According to several authors (e.g. [18-23]), both the diffuse and Stern layers contribute to the specific surface conductance:

$\Sigma_{s}=\Sigma_{s}^{\text {diffuse }}+\Sigma_{s}^{\text {Stern }}$

The Stern layer contribution can be described by [50, 53]:

$\Sigma_{s}^{\mathrm{Stern}}=\sum_{i} z_{i} e \beta_{i}^{\mathrm{St}} \Gamma_{i}^{\mathrm{St}}$

where the superscript "St" corresponds to the Stern layer, and $\Gamma_{i}^{\mathrm{St}}$ is the surface site density of adsorbed counterions at the Stern layer (in sites $\mathrm{m}^{-2}$ ). Eq. (56) describes the lateral movement of adsorbed cations and anions [56, 57], and consequently assumes that the ion species are not immobile in the Stern layer [16]. The ion mobility values at the Stern layer are still relatively unknown. For clay minerals and quartz, Revil and Glover [50] and Revil et al. [58] considered that the ion mobilities of several cations like $\mathrm{Na}^{+}, \mathrm{K}^{+}, \mathrm{Ca}^{2+}$ are at least one order of magnitude smaller than those in the bulk electrolyte. For silica minerals, Leroy et al. [15] have hypothesized that the surface ion mobilities are similar to those of the bulk. Molecular dynamics simulations at the solid/water interface must be of particular importance to characterize the ion and water mobilities in the compact layer. For example, in their work concerning the characterization of the surface properties of rutile, Predota et al. [32] considered a surface water mobility that is $10 \%$ of the bulk ion mobility at $3.7 \AA$ from the surface. According to Eqs. (54) to (56), the total surface conductance of a particle can be described by: 


$$
\begin{aligned}
& \Sigma_{s}=2 \kappa^{-1} F z\left\{\left(c_{(+)}^{b} B_{(+)}+1000 \times 10^{-\mathrm{pH}} B_{\mathrm{H}^{+}}\right)\left[\exp \left(\frac{-F z \psi_{d}}{2 R T}\right)-1\right]\right. \\
& +\left(c_{(-)}^{b} B_{(-)}+1000 \times 10^{\mathrm{pH}-\mathrm{p} K_{f}} B_{\mathrm{OH}^{-}}\left[\exp \left(\frac{F z \psi_{d}}{2 R T}\right)-1\right]\right\}+\sum_{i} z_{i} e \beta_{i}^{\mathrm{St}} \Gamma_{i}^{\mathrm{St}} .
\end{aligned}
$$

As seen by Eq. (57), it is easy to estimate surface conductance if the electrical potential at the head end of the diffuse layer $\psi_{d}$ and the surface sites $\Gamma_{i}^{\mathrm{St}}$ are known. These parameters can be estimated by a complete surface complexation model of the $\mathrm{TiO}_{2} /$ water interface. The ion mobilities of the counterions in the compact layer $\beta_{i}^{\mathrm{St}}$ are the only unknown.

Below, we use this approach to determine the zeta potential of $\mathrm{TiO}_{2}$ nanoparticles using the particle size and the electrophoretic mobility data of Foissy [3].

\section{Comparison with experimental data}

\subsection{Modeling strategy}

Firstly, the function $f(\kappa a)$ is determined according to Eqs. (12), (20) and (21). Secondly, titanium dioxide surface complexation models estimate the surface conductance of the double layer $\Sigma_{s}$ (Eq. (57)). The subsequent calculation of the electrical conductivity of the bulk electrolyte based on its ion composition, $\sigma_{b}$, (Eq. (34)) and the radius of an agglomerate made up of elementary particles, $a$, make it possible to determine the Dukhin number, Du (Eq. 19). Thirdly, the parameter corresponding to the electrical conductivity of the agglomerate's interior, $K_{p}$, is calculated thanks to Eqs. (26) to (28) for a given value of the intra-aggregate porosity $\phi$ and elementary particle's radius $a_{e}$. Finally, the zeta potential is estimated from the electrophoretic measurements using the calculated values of $f(\kappa a)$, Du, $K_{p}$, and Eq. (22) for the case of Henry's theory (see Fig. 5). By comparison, the von Smoluchowski equation (Eq. (11)) is also used to convert 
electrophoretic mobilities to zeta potential values. The surface complexation calculations were done with PHREEQC v2.17 [28] and the conversion calculations were done using a MATLAB routine.

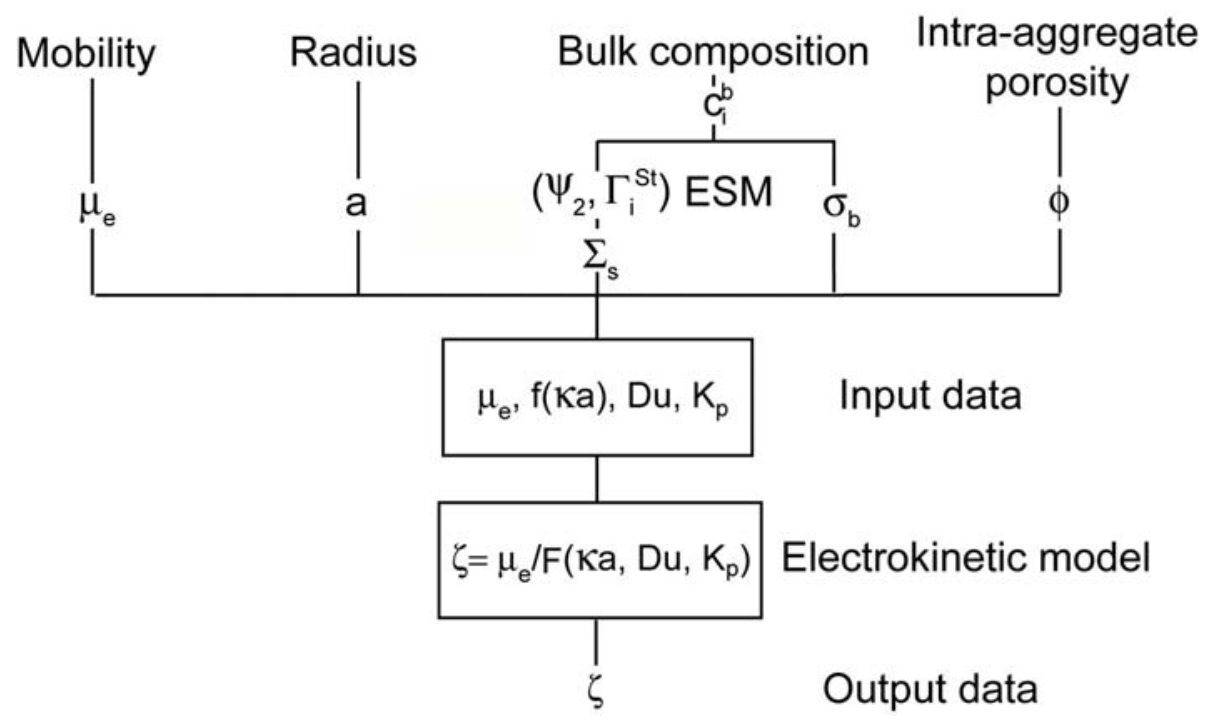

Fig. 5. Modeling strategy for determining the zeta potential from electrophoresis.

Raw electrophoretic measurements are necessary for these calculations. Unfortunately, only pre-processed zeta potentials are available in most publications. Foissy [3] provides electrophoretic measurements for titanium dioxide P25 for a wide range of electrolyte concentrations but in a $\mathrm{NaCl}$ electrolyte background. According to the comparative modeling of Bourikas et al. [9], $\mathrm{NO}_{3}{ }^{-}$and $\mathrm{Cl}^{-}$behave similarly at the $\mathrm{TiO}_{2}$ surface. This could be verified by satisfactorily reproducing the surface charge data that Ridley et al. [2] obtained on the anatase ST-01 using the same model as the ESM listed in Table 1 and the same parameters for $\mathrm{Cl}^{-}$as for $\mathrm{NO}_{3}{ }^{-}$(not shown).

\subsection{Input data of the electrokinetic model}

Foissy [3] did titration and electrophoretic measurements on $\mathrm{TiO}_{2}$ P25 (Degussa, Germany). The crystalline form is anatase (95\%). The density measured by helium 
pycnometry after drying is $3.76 \mathrm{~g} \mathrm{~cm}^{-3}$. The estimated specific surface area (using $\mathrm{N}_{2}$ adsorption and immersion calorimetry) is $54 \pm 3 \mathrm{~m}^{2} \mathrm{~g}^{-1}$. The size of an elementary particle is approximately $30 \mathrm{~nm}$, but P25 nanoparticles can form aggregates measuring several micrometers [1]. Foissy [3] measured electrophoretic mobilities for $\mathrm{pH}$ values comprised between 4 and 11 , and salinities $(\mathrm{NaCl})$ of $10^{-4}, 10^{-3}$, and $10^{-2} \mathrm{M}$. Furthermore, he used X-ray measurements to obtain the particle size distribution as a function of $\mathrm{pH}$ at $10^{-3} \mathrm{M}$.

At $10^{-3} \mathrm{M}$, we use a normal distribution in agreement with the particle size distribution measured by Foissy [3] and calculate the Debye length to estimate the function $f(\kappa a)$. For other salinities, we also use a normal distribution for the particle size. Eqs. (12), (48) and (57) make it possible to calculate the specific surface conductance using the values of $\psi_{2}\left(\psi_{2}=\psi_{d}\right.$ here $), \Gamma_{\mathrm{Na}}^{\mathrm{St}}, \Gamma_{\mathrm{Cl}}^{\mathrm{St}}$ determined by the ESM surface complexation model (Fig. 6). The $\mathrm{Na}^{+}, \mathrm{Cl}^{-}, \mathrm{H}^{+}$and $\mathrm{OH}^{-}$ion mobility values in the bulk and diffuse layer $\left(\beta_{i}\right)$ are $5.17,7.89,36.20$, and $20.49 \times 10^{-8} \mathrm{~m}^{2} \mathrm{~s}^{-1} \mathrm{~V}^{-1}$, respectively (from PHREEQC's phreeqd.dat database). The ion mobilities at the Stern layer remain unknown. We used $\beta_{i}^{\text {St }}=\beta_{i}$, according to the surface conductivity model of Leroy et al. [15] for silica minerals, to estimate surface conductance. Surface conductance increases significantly with salinity and with the difference between $\mathrm{pH}$ and IEP (6.5 here) (Fig. 6). Note that we restrict the investigated $\mathrm{pH}$ range at $10^{-4}$ and $10^{-3} \mathrm{M}$ to have a constant ionic strength. 

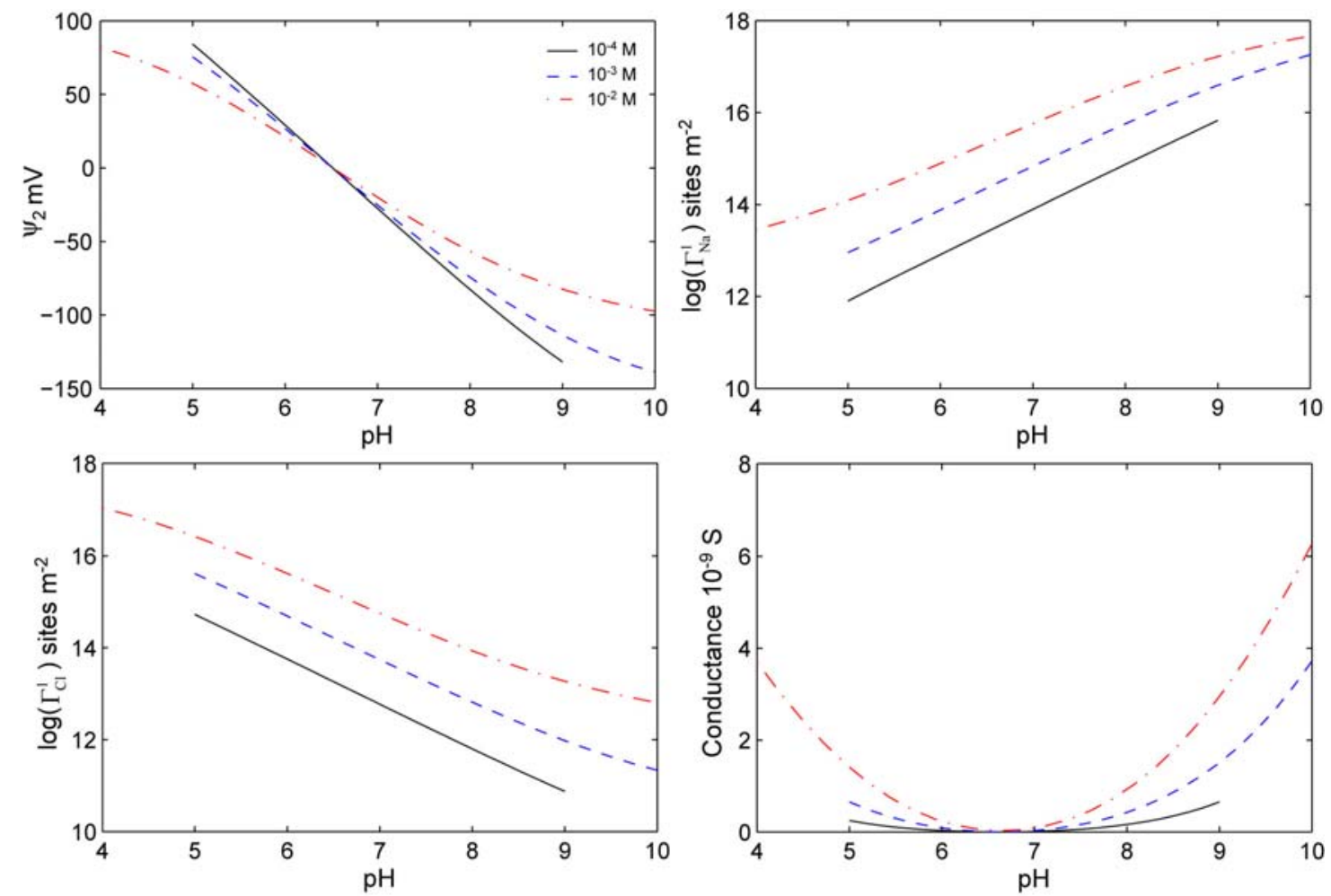

Fig. 6. The electrical potential at the 2-plane, the surface site densities of adsorbed sodium and chloride at the Stern layer (1-plane), and the surface conductance versus $\mathrm{pH}$ for three salinities $(\mathrm{NaCl})$.

According to Eq. (19), the Dukhin number (Du) is determined using (1) a normal distribution for the particle size $a$ (in agreement at $10^{-3} \mathrm{M}$ with the particle size distribution measured by Foissy [3]), (2) the estimated surface conductance $\Sigma_{s}$, and (3) the electrical conductivity of the bulk electrolyte $\sigma_{b}$. The fitting parameters are the intraaggregate porosity $\phi$ and the PSD at $10^{-4}$ and $10^{-2} \mathrm{M}$.

\subsection{Zeta potentials from electrophoretic data}

According to the particle size measurements of Foissy at $10^{-3} \mathrm{M}$ [3] (Fig. 7), titanium dioxide nanoparticles are highly agglomerated at $\mathrm{pH}$ values close to the IEP, leading to 20- $\mu \mathrm{m}$ agglomerates. At extreme $\mathrm{pH}$ values $(\mathrm{pH}=4, \mathrm{pH}=10)$ agglomerates reach sizes 
comprised between one and three micrometers. Thus, $\kappa a>>1$ and increases significantly at $\mathrm{pH}$ values close to the IEP. As a result, the Dukhin number is low in amplitude except for basic $\mathrm{pH}$ where it increases strongly (Fig. 7). Zeta potentials inferred from electrophoresis using our model are in very good agreement with the ESM predictions assuming $\psi_{2}=\psi_{d}$ (Fig. 7). We use $\phi=0.4$, which is in accordance with the intraaggregate porosity value measured recently by Xu et al. [59] for P25 $(\phi=0.38)$ from the $\mathrm{N}_{2}$ desorption isotherm using the cylindrical pore model (BJH method). The zeta potential calculations using the Smoluchowski equation are also presented by comparison. Their amplitudes are not in agreement with the ESM predictions because the Smoluchowski equation neglects surface conductivity.

PSD found at other salinities seem to be physically realistic (Fig. 8). Size of agglomerated nanoparticles is $\mathrm{pH}$-and salinity-dependent, and increases significantly close to the IEP and at high ionic strength. The Dukhin number also diminishs significantly in these physico-chemical conditions. In addition, for $10^{-4}$ and $10^{-2} \mathrm{M}$, zeta potentials calculated from electrophoresis using our modeling approach are also in very good agreement with the ESM predictions (Fig. 9), except for $\mathrm{pH}$ values close to the IEP. We use $\phi=0.4$.

Our modeling results suggest that the shear plane may be located close to the OHP, in contradiction with the hypothesis of a stagnant diffuse layer having a salinity-dependant thickness at the $\mathrm{TiO}_{2}$ water interface $[1,9]$. 

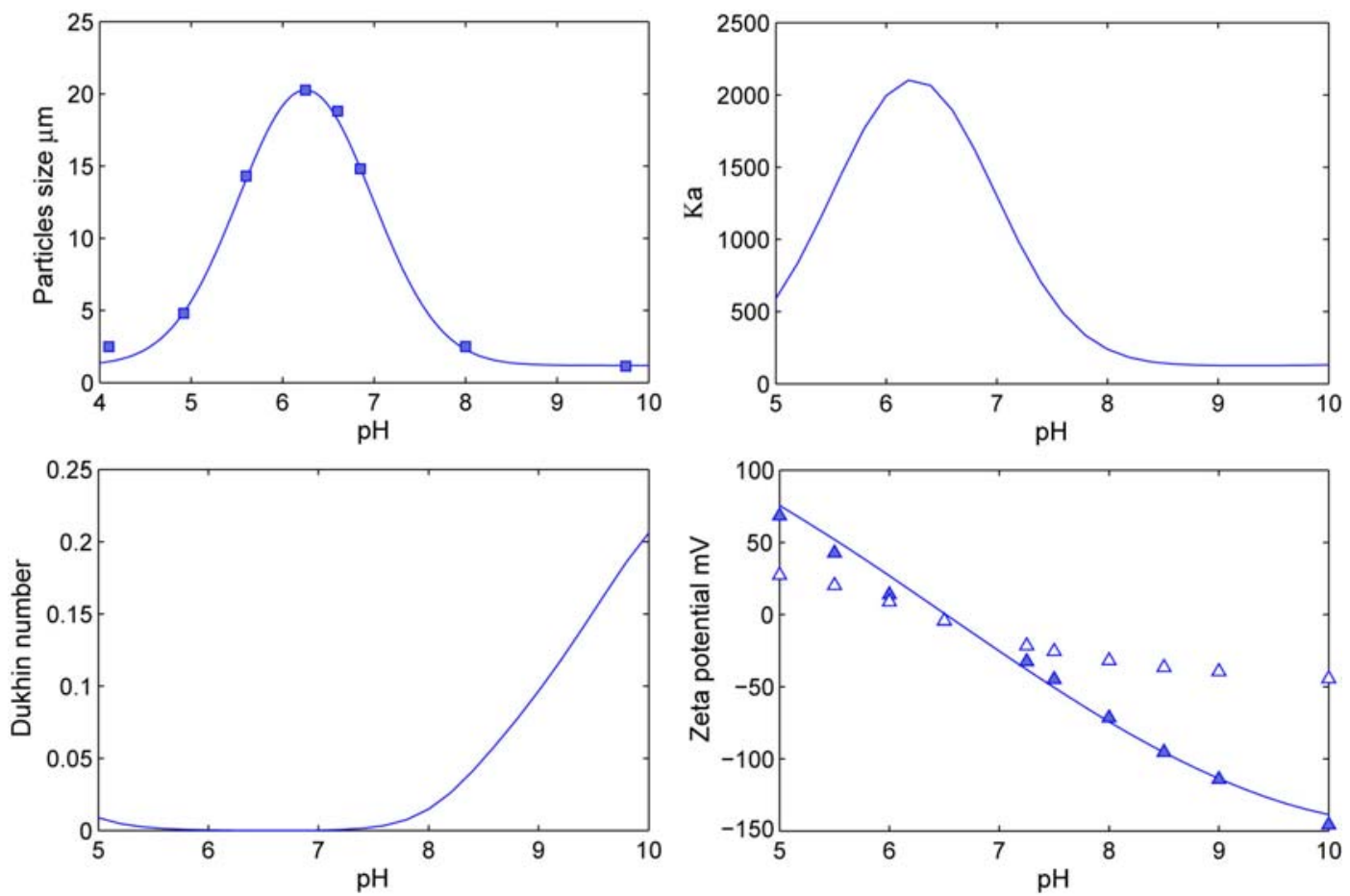

Fig. 7. Input data of the model of Henry [40] and zeta potentials versus $\mathrm{pH}$ at $10^{-3} \mathrm{M}$ from electrophoresis (full triangles, our model; empty triangles, Smoluchowski equation's predictions). The line on zeta potential figure is the ESM prediction assuming $\psi_{2}=\psi_{d}$.
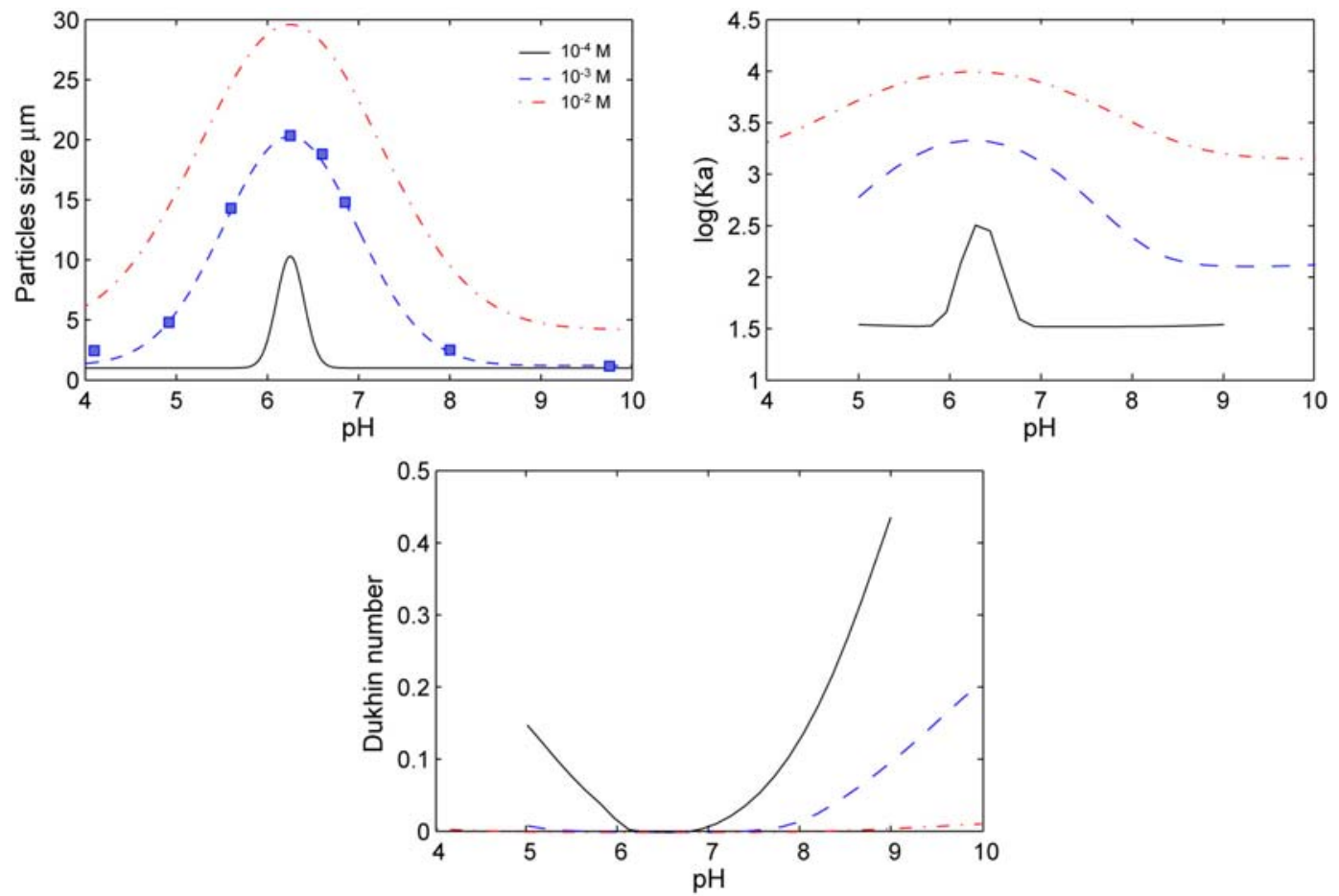

Fig. 8. Input data of the model of Henry [40] versus $\mathrm{pH}$ at $10^{-4}, 10^{-3}$, and $10^{-2} \mathrm{M}$. 

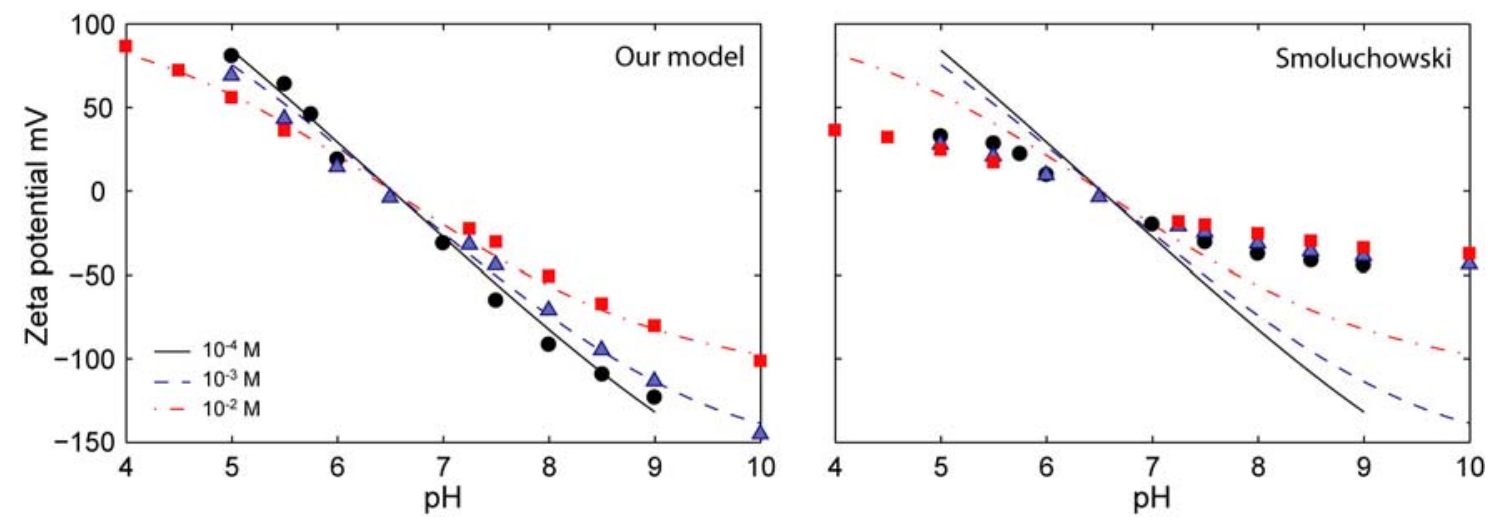

Fig. 9. Zeta potentials versus $\mathrm{pH}$ at $10^{-4}, 10^{-3}$, and $10^{-2} \mathrm{M}$ from electrophoresis. The lines are the ESM predictions assuming $\psi_{2}=\psi_{d}$.

\section{Conclusions}

We have developed an extended Stern layer model to characterize the electrochemical properties of titanium dioxide in a 1:1 electrolyte $(\mathrm{NaCl})$. This model significantly lowers the amplitude of electrical potential at the OHP compared to that of other recent surface complexation models [1,9] without altering the quality of the titration data predictions.

Henry's model [40] is used to convert electrophoretic mobility measurements to zeta potential values taking into account agglomerate's size and surface conductance. Electrical conductivity inside the agglomerate is calculated using the differential selfconsistent model of Sen et al. [47]. The theory of particle's surface conductance due to the diffuse and Stern layers is described in depth.

By combining the excess of electrical charge calculated at the compact Stern layer and in the diffuse layer with Henry's equations [40], we show that the shear plane may be located close to the OHP, contradicting the assumption of the presence of a stagnant diffuse layer at the $\mathrm{TiO}_{2} /$ water interface as mentioned by Bourikas et al. [9] and Panagiotou et al. [1]. 
In the future, we will use a numerical model to convert electrophoretic and electrical conductivity measurements to zeta potential values under arbitrary conditions including high zeta potential amplitudes, particle volume fraction, polydispersity of the sample, diffuse layer overlapping, and surface conductance. In addition, we will compare our modeling results to a much more refined set of experiments (spherical and monodisperse/polydisperse particles) including electrical conductivity measurements.

\section{Acknowledgments}

This study was done within the framework of the NANOSEP Project (ANR-08-ECOT009). The authors are grateful to French National Research Agency for financial support. 


\section{References}

1. G. D. Panagiotou; T. Petsi; K. Bourikas; C. S. Garoufalis; A. Tsevis; N. Spanos; C. Kordulis; A. Lycourghiotis, Advances in Colloid and Interface Science 2008, 142, (1-2), 20-42.

2. M. K. Ridley; V. A. Hackley; M. L. Machesky, Langmuir 2006, 22, (26), 1097210982.

3. A. Foissy. Analysis of adsorption of ions and polyacrylic acids in aqueous dispersions of titane dioxide. PhD thesis, Faculté des Sciences et des Techniques de l'Université de Franche-Comté-Besançon, 1985.

4. A. Foissy; A. Mpandou; J. M. Lamarche; N. Jaffrezicrenault, Colloids and Surfaces 1982, 5, (4), 363-368.

5. N. Kallay; M. Colic; D. W. Fuerstenau; H. M. Jang; E. Matijevic, Colloid and Polymer Science 1994, 272, (5), 554-561.

6. T. Hiemstra; W. H. Van Riemsdijk, Journal of Colloid and Interface Science 1996, 179, 488-508.

7. T. Hiemstra; P. Venema; W. H. Van Riemsdijk, Journal of Colloid and Interface Science 1996, 184, 680-692.

8. N. Sahai; D. A. Sverjensky, Geochimica Et Cosmochimica Acta 1997, 61, (14), 2801-2826.

9. K. Bourikas; T. Hiemstra; W. H. Van Riemsdijk, Langmuir 2001, 17, (3), 749756.

10. D. A. Sverjensky, Geochimica et Cosmochimica Acta 2005, 69, (2), 225-257.

11. J. Lyklema, Fundamentals of interface and colloid science: Liquid-fluid interfaces. Academic Press: London, 1995.

12. R. J. Hunter, Zeta Potential in Colloid Science: Principles and Applications. Academic Press: New York, 1981.

13. B. V. Derjaguin; L. Landau, Acta Physico-Chimica (URSS) 1941, 14, 633-662.

14. A. Revil; P. Leroy, Journal of Geophysical Research-Solid Earth 2004, 109, B03208, 10.1029/2003JB002755.

15. P. Leroy; A. Revil; A. Kemna; P. Cosenza; A. Ghorbani, Journal of Colloid and Interface Science 2008, 321, (1), 103-117.

16. C. Tournassat; Y. Chapron; P. Leroy; M. Bizi; F. Boulahya, Journal of Colloid and Interface Science 2009, 339, 533-541.

17. P. Leroy; A. Revil; S. Altmann; C. Tournassat, Geochimica et Cosmochimica Acta 2007, 71, (5), 1087-1097.

18. J. Lyklema; S. S. Dukhin; V. N. Shilov, Journal of Electroanalytical Chemistry 1983, 143, (1-2), 1-21.

19. C. F. Zukoski; D. A. Saville, Journal of Colloid and Interface Science 1986, 114, (1), 32-44.

20. C. F. Zukoski; D. A. Saville, Journal of Colloid and Interface Science 1986, 114, (1), 45-53.

21. C. S. Mangelsdorf; L. R. White, Journal of the Chemical Society-Faraday Transactions 1990, 86, (16), 2859-2870.

22. C. S. Mangelsdorf; L. R. White, Journal of the Chemical Society-Faraday Transactions 1998, 94, (17), 2583-2593.

23. C. S. Mangelsdorf; L. R. White, Journal of the Chemical Society-Faraday Transactions 1998, 94, (16), 2441-2452.

24. V. E. Shubin; R. J. Hunter; R. W. Obrien, Journal of Colloid and Interface Science 1993, 159, (1), 174-183. 
25. J. Sonnefeld; M. Lobbus; W. Vogelsberger, Colloids and Surfaces aPhysicochemical and Engineering Aspects 2001, 195, (1-3), 215-225.

26. M. L. Jimenez; F. J. Arroyo; F. Carrique; A. V. Delgado, Journal of Colloid and Interface Science 2007, 316, (2), 836-843.

27. N. Spanos; A. Tsevis; P. G. Koutsoukos; M. Minor; A. van der Linde; J. Lyklema, Colloids and Surfaces a-Physicochemical and Engineering Aspects 1998, 141, (1), 101-109.

28. D. L. Parkhurst; C. A. J. Appelo 1999, User's guide to PHREEQC (Version 2) - A computer program for speciation, batch-reaction, one-dimensional transport, and inverse geochemical calculations.

29. A. Tilocca; A. Selloni, Langmuir 2004, 20, (19), 8379-8384.

30. A. Tilocca; A. Selloni, Journal of Physical Chemistry B 2004, 108, (15), 47434751.

31. M. Predota; A. V. Bandura; P. T. Cummings; J. D. Kubicki; D. J. Wesolowski; A. A. Chialvo; M. L. Machesky, Journal of Physical Chemistry B 2004, 108, (32), 12049-12060.

32. M. Predota; P. T. Cummings; D. J. Wesolowski, Journal of Physical Chemistry C 2007, 111, (7), 3071-3079.

33. M. Predota; L. Vlcek, Journal of Physical Chemistry B 2007, 111, (5), 1245-1247.

34. M. Predota; Z. Zhang; P. Fenter; D. J. Wesolowski; P. T. Cummings, Journal of Physical Chemistry B 2004, 108, (32), 12061-12072.

35. T. Hiemstra; W. H. Van Riemsdijk, Journal of Colloid and Interface Science 2006, 301, (1), 1-18.

36. M. Von Smoluchowski, in: Handbuch der Elektrizitat und des Magnetismus, L. Graetz, (Ed.) Barth, Leipzig, 1921; Vol. II, pp 366-428.

37. M. Von Smoluchowski, Bulletin International de l'Academie des Sciences de Cracovie 1903, 8, 182-200.

38. E. Hückel, Physikalische Zeitschrift 1924, 25, 204-210.

39. D. C. Henry, Proc. R. Soc. Lond. A 1931, 133, 106-129.

40. D. C. Henry, Transactions of the Faraday Society 1948, 44, 1021-1026.

41. S. S. Dukhin; V. N. Shilov, Dielectric phenomena and the double layer in disperse systems and polyelectrolytes. John Wiley and Sons: New York, 1974.

42. A. Crespy; A. Boleve; A. Revil, Journal of Colloid and Interface Science 2007, 305, (1), 188-194.

43. R. W. O'Brien, Journal of Colloid and Interface Science 1986, 113, (1), 81-93.

44. R. W. Obrien; D. N. Ward, Journal of Colloid and Interface Science 1988, 121, (2), 402-413.

45. S. Ahualli; F. J. Arroyo; A. V. Delgado, Journal of Colloid and Interface Science 2010, 343, (1), 350-358.

46. F. Carrique; F. J. Arroyo; A. V. Delgado, Journal of Colloid and Interface Science 2002, 252, (1), 126-137.

47. P. N. Sen; C. Scala; M. H. Cohen, Geophysics 1981, 46, (5), 781-795.

48. A. Revil, Journal of Geophysical Research-Solid Earth 2000, 105, (B7), 1674916768.

49. R. W. O'Brien; D. W. Cannon; W. N. Rowlands, Journal of Colloid and Interface Science 1995, 173, (2), 406-418.

50. A. Revil; P. W. J. Glover, Geophysical Research Letters 1998, 25, (5), 691-694.

51. A. Revil; P. W. J. Glover, Physical Review B 1997, 55, (3), 1757-1773.

52. S. R. De Groot; P. Mazur, Non-equilibrium thermodynamics. North-Holland Pub. Co.: Amsterdam, 1962. 
53. P. Leroy; A. Revil, Journal of Colloid and Interface Science 2004, 270, (2), 371380.

54. S. Pride, Physical Review B 1994, 50, (21), 15678-15696.

55. J. J. Bikerman, Transactions of the Faraday Society 1940, 36, 154-160.

56. C. T. O'Konski, Journal of Physical Chemistry 1960, 64, 605-619.

57. J. M. Schurr, Journal of Physical Chemistry 1964, 68, 2407-2413.

58. A. Revil; L. M. Cathles; S. Losh; J. A. Nunn, Journal of Geophysical ResearchSolid Earth 1998, 103, (B10), 23925-23936.

59. J. H. Xu; W. L. Dai; J. Li; Y. Cao; H. Li; K. Fan, Journal of Photochemistry and Photobiology a-Chemistry 2008, 195, 284-294. 
Table 1. Surface and interface parameters for the Panagiotou et al. model [1] and alternative models.

\begin{tabular}{|c|c|c|c|c|c|}
\hline Parameters & $\begin{array}{l}\text { Original } \\
\text { Panagiotou et } \\
\text { al. model }\end{array}$ & $\begin{array}{l}\text { Reference } \\
\text { model (TPM) }\end{array}$ & BSM & ESM & Bidentate \\
\hline $\log K_{1}$ & 7.8 & 7.6 & 7.6 & 7.55 & 7.55 \\
\hline $\log K_{2}$ & 4.6 & 4.2 & 4.2 & 4.15 & 4.15 \\
\hline $\log \mathrm{K}_{\mathrm{Na}(\mathrm{K})}$ & $-1.7(-1.1)$ & $-1.7(-1.1)$ & $-1.7(-1.7)$ & $-1.4(-1.1)$ & -1 \\
\hline $\log \mathrm{K}_{\mathrm{NO} 3}$ & -2.3 & -2.3 & $-99^{*}$ & -1.5 & -1.5 \\
\hline$\Delta \mathrm{z}_{0 \mathrm{Na}}$ & - & - & - & - & 0.55 \\
\hline$\Delta \mathrm{Z}_{1 \mathrm{Na}(\mathrm{K})}$ & $0.7(0)$ & $0.7(0)$ & n.a. & $1(0.7)$ & $0.45(0.7)$ \\
\hline$\Delta \mathrm{Z}_{2 \mathrm{Na}(\mathrm{K})}$ & $0.3(1)$ & $0.3(1)$ & n.a. & $0(0.3)$ & $0(0.3)$ \\
\hline$\Delta \mathrm{z}_{1 \mathrm{NO}}$ & -0.7 & -0.7 & n.a. & -1 & -1 \\
\hline$\Delta \mathrm{z}_{2 \mathrm{NO} 3}$ & -0.3 & -0.3 & n.a. & 0 & 0 \\
\hline$C_{1}\left(\mathrm{~F} \mathrm{~m}^{-2}\right)$ & 3.2 & 3.2 & 2.5 & 2.5 & 2.5 \\
\hline$C_{2}\left(\mathrm{~F} \mathrm{~m}^{-2}\right)$ & 4.2 & 4.2 & $\infty$ & 1 & 1 \\
\hline
\end{tabular}

* In the $\mathrm{BSM}, \mathrm{NO}_{3}{ }^{-}$anions act as indifferent anions 


\section{Figure captions}

Fig. 1. Schematic drawing of the basic Stern model of Bourikas et al. [9], our basic Stern model, the triple plane model of Panagiotou et al. [1], and our extended Stern model for a negatively charged surface of titanium dioxide. At a given picture, from left to right: metal ions, surface hydroxyls, primary and secondary water layers, compact layer, diffuse layer.

Fig. 2. $\mathrm{TiO}_{2}$ surface charge and potential at the head end of the diffuse layer predicted by different surface complexation models at three ionic strengths in $\mathrm{NaNO}_{3}$. Lines depict the reference model (TPM) results while symbols depict the results of alternative models (BSM, ESM, Bidentate, Table 1).

Fig. 3. $\mathrm{TiO}_{2}$ surface properties predicted by different surface complexation models at three ionic strengths in $\mathrm{KNO}_{3}$. Lines depict the TPM reference model results while symbols depict the results of alternative models (Table 1).

Fig. 4. Schematic representation of the electro-chemical properties of a suspension of spherical oxide nanoparticles. The particle has a local excess of electrical conductivity at its interface $\sigma(\chi)$. The surface conductance $\Sigma_{s}$ is estimated by integrating $\sigma(\chi)-\sigma_{b}$ over the thickness of the Stern and diffuse layers.

Fig. 5. Modeling strategy for determining the zeta potential from electrophoresis.

Fig. 6. The electrical potential at the 2-plane, the surface site densities of adsorbed chloride and sodium at the Stern layer (1-plane), and the surface conductance versus $\mathrm{pH}$ for three salinities $(\mathrm{NaCl})$.

Fig. 7. Input data of the model of Henry [40] and zeta potentials versus $\mathrm{pH}$ at $10^{-3} \mathrm{M}$ from electrophoresis (full triangles, our model; empty triangles, Smoluchowski equation's predictions). The line on zeta potential figure is the ESM prediction assuming $\psi_{2}=\psi_{d}$. 
Fig. 8. Input data of the model of Henry [40] versus $\mathrm{pH}$ at $10^{-4}, 10^{-3}$, and $10^{-2} \mathrm{M}$.

Fig. 9. Zeta potentials versus $\mathrm{pH}$ at $10^{-4}, 10^{-3}$, and $10^{-2} \mathrm{M}$ from electrophoresis. The lines are the ESM predictions assuming $\psi_{2}=\psi_{d}$. 